\title{
Gesundheit - Sein oder Haben?
}

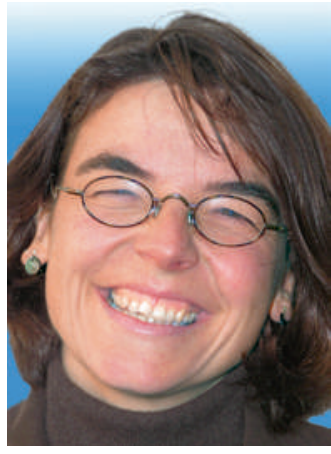

Christina Aus der Au
Mittlerweile wissen es alle - unsere Privatsphäre ist alles andere als privat. Die NSA hört mit bei den Telefonaten von Politikern und Politikerinnen und liest mit bei ihren E-Mails. Google und Amazon wissen alles über unsere Interessen und Lesegewohnheiten, und Facebook und Twitter kennen unsere Freunde, unsere Hobbys und unsere Launen. Und es gibt Zeitgenoss(inn)en, die sich über eine solche Bespitzelung empören, und andere, die mit den Schultern zucken. Und wieder andere schlagen mehr oder weniger ernsthaft vor, dass man die Privatsphäre gleich ganz abschaffen soll: Eine solche Geheimniskrämerei sei sowieso asozial und grundsätzlich verdächtig.

Einer der neuen Trends in der Medizin unterstützt diese letzte Position. Die neue Lehre lautet: Dinge über sich geheim halten zu wollen ist kurzsichtig und schadet letztlich dem Individuum selber. Je mehr jemand nämlich über sich, seine Gesundheit, seine genetische Ausstattung und seine Lebensweise weiss, desto besser kann er oder sie Vorsorge gegen Krankheiten treffen und desto treffsicherer kann er oder sie therapiert werden. Personalisierte Medizin und «personalized genomics» sind die vielversprechenden Schlagwörter, und weltweit bieten mittlerweile über 30 Firmen individuelle DNA-Tests an, mittels derer man seine Gesundheitsrisiken und entsprechend angepasste Medikamente herausfinden kann [1].

Noch interessanter, weil noch umfassender, sind allerdings die unzähligen Apps, mit denen Smartphonebesitzer/-innen ihren Blutdruck, ihre Fitnessaktivitäten und ihre Essgewohnheiten registrieren. Wie viele Schritte ich pro Tag tue, wie viele Kalorien ich zu mir nehme, wie viele Male mein Blutdruck in die Höhe jagt, wie viele Stunden ich in welcher Schlafphase verbringe - all diese Daten müssen irgendwo gespeichert werden. Wenn nun ein gigantischer Zentralcomputer Zugang dazu hätte und sie personalisiert auswerten könnte, dann - ja, dann könnte dieser aus diesen Daten für mich und Dich, für Sie und uns und Euch alle eine persönliche und umfassende Gesundheitsanalyse und Lebensberatung erstellen. Und das wäre doch sehr hilfreich, oder?

Auf der Basis dieser ungeheuren Information könnte sich die Medizin und auch die Pharmaindustrie dahingehend verändern, dass sie nicht mehr einfach den Durchschnittspatienten im Blick haben. Stattdessen werden Therapien und Medikamente massgeschneidert sein für jeden einzelnen Patienten. Dazu ist keine umfassende Anamnese mehr nötig, sondern die gläserne Patientin ist auf Knopfdruck abrufbar.

Diese Entwicklung wird dazu führen, so sagen Fachleute, dass die Kontrolle und die Verantwortung für unsere Gesundheit von der Ärztin zum Patienten verschoben wird [2]. Je mehr wir über uns und unsere Verfassung wissen, desto mehr sind wir daran schuld, wenn wir nichts gegen die Risiken unternehmen. Dazu gehört nicht nur der Umgang mit genetischen Risikofaktoren für Brustkrebs, Schizophrenie und Alkoholismus [3], sondern auch mit einer möglichen genetischen Prädisposition für Suizid [4].

Wer mehr weiss, kann mehr verhindern. Und wer das nicht will, wer seine Daten nicht aufnimmt und nicht zur Verfügung stellt, ist selber schuld. Und eben auch asozial, denn wenn man mehr Daten hat, können die Einzeldaten auch aussagekräftiger und damit nutzbringender auch für andere ausgearbeitet werden. Und so sind wir nicht nur für unsere eigene Gesundheit verantwortlich, sondern auch für diejenige anderer.

Aber mehr noch: Wir sind nicht nur verantwortlich dafür, wir definieren sie! Dasjenige, was wir an uns beobachten, messen, wiegen, zählen, fliesst ein in unser Bild, was wie zu sein hat, damit wir gesund sind. Gesundheit ist dann nicht mehr ein Sein, sondern ein Haben. Wir haben die richtigen Gene, Masse und Gehirnstrukturen. Oder eben nicht. Wir haben die richtige Lebensweise, die richtige Ernährung, den richtigen Wohn- und Arbeitsort, die richtige Lebenseinstellung. Und wir haben gefälligst rund um die Uhr dafür zu sorgen.

Damit sind wir dann ziemlich beschäftigt. Das gesunde (und lange) Leben wird jedenfalls sehr anstrengend sein. Und ziemlich selbstbezogen. Die protestantische Tradition hat dafür einen Namen: incurvatus in se ipse, in sich selbst verkrümmt. Oder wenn man es noch historischer haben will: Sünde.

Christina Aus der $A u^{*}$

1 www.isogg.org/wiki/List_of_personal_genomics_ companies (13.8.2014).

2 «The sum of this information could transform medicine, turning a field aimed at treating the average patient into one that's customized to each person while shifting more control and responsibility from doctors to patients.» www.technologyreview.com/ news/529011/can-technology-fix-medicine/ (13.8.2014).

3 www.medicalnewstoday.com/articles/279908.php (13.8.2014).

4 www.technologyreview.com/news/530121/could-agenetic-test-predict-the-risk-for-suicide/ (13.8.2014). 